\title{
Discriminating between large-scale oil palm plantations and smallholdings on tropical peatlands using vegetation indices and supervised classification of LANDSAT-8
}

\begin{abstract}
Tropical peat swamp forest is rapidly being converted into industrial-scale oil palm agriculture across South-east Asia. This has global and local environmental implications including habitat loss and carbon release. Monitoring oil palm expansion or land-use/land-cover on peatlands is feasible using remote sensing technology, however, there are few examples of assessments of different oil palm management systems. Three peatland land cover types were assessed and mapped using vegetation indices and supervised classifications of Landsat-8 level-2 imagery: peat swamp forest, large-scale oil palm plantation and smallholding. Firstly, we calculated and compared differences in vegetation indices (NDVI, EVI and SAVI) values between each of the land covers. Next, we mapped land cover using three classification methods - Support Vector Machine, Random Trees and Maximum Likelihood - with a single date and multi-temporal datasets. These were applied to the vegetation indices and also a three band Landsat image using band 2 (blue band), band 4 (red band) and band 5 (near-infrared band) i.e. false colour composite. The vegetation index assessment found significant differences in the NDVI, EVI and SAVI between peat swamp forest, large-scale plantation and smallholding. The NDVI in peat swamp forest was highest. In contrast, the EVI and SAVI in the peat swamp forest were the lowest. While the NDVI, EVI and SAVI in the large-scale plantations were greater than the smallholdings. Irrespective of landscape type, there were strong positive correlations between NDVI and EVI, NDVI and SAVI, and EVI and SAVI. For the land cover mapping, the best classifier was Random Trees with the multi-temporal Landsat bands 543 datasets with a mapping accuracy of $95.54 \%$ and a Kappa coefficient of 0.933 . This study demonstrated that both vegetation indices and land cover mapping can provide planners and decision-makers with tools to monitor natural and production landscapes, managed under different systems in the tropics.
\end{abstract}

Keyword: Oil palm plantations; Tropical peatlands; LANDSAT-8 